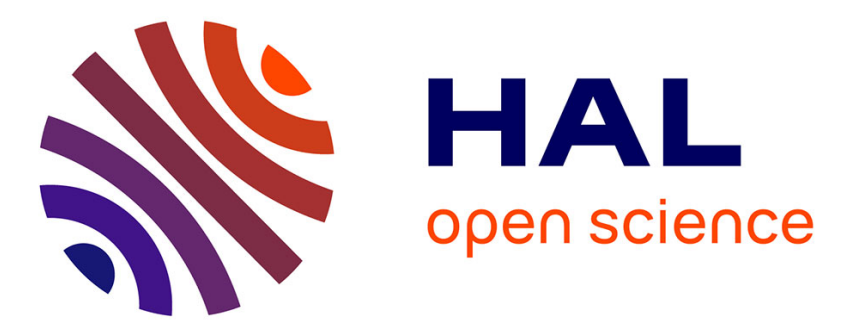

\title{
Molecular evidence for multiple introductions of the banded grove snail (Cepaea nemoralis) in North America
}

Kara K.S. Layton, Connor Patrick Warne, Annegret Nicolai, Armelle Ansart, Jeremy Dewaard

\section{- To cite this version:}

Kara K.S. Layton, Connor Patrick Warne, Annegret Nicolai, Armelle Ansart, Jeremy Dewaard. Molecular evidence for multiple introductions of the banded grove snail (Cepaea nemoralis) in North America. Canadian Journal of Zoology, 2019, 97 (4), pp.392-398. 10.1139/cjz-2018-0084 . hal-01970952

HAL Id: hal-01970952

https://hal-univ-rennes1.archives-ouvertes.fr/hal-01970952

Submitted on 2 Sep 2020

HAL is a multi-disciplinary open access archive for the deposit and dissemination of scientific research documents, whether they are published or not. The documents may come from teaching and research institutions in France or abroad, or from public or private research centers.
L'archive ouverte pluridisciplinaire HAL, est destinée au dépôt et à la diffusion de documents scientifiques de niveau recherche, publiés ou non, émanant des établissements d'enseignement et de recherche français ou étrangers, des laboratoires publics ou privés. 
Molecular evidence for multiple introductions of the banded grove snail (Cepaea nemoralis) in North America

K.K.S. Layton ${ }^{1}$, C.P.K. Warne ${ }^{2 *}$, A. Nicolai ${ }^{3}$, A. Ansart ${ }^{4}$, and J.R. deWaard ${ }^{5,2}$

${ }^{1}$ Centre for Evolutionary Biology, The University of Western Australia, 35 Stirling Hwy, Crawley, Western Australia, Australia, 6009

${ }^{2}$ School of Environmental Sciences, University of Guelph, 50 Stone Road East, Guelph, Ontario, Canada, N1G 2W1

${ }^{3}$ Université Rennes, UMR CNRS 6553 EcoBio/OSUR, Station Biologique Paimpont, 35380

Paimpont, France

${ }^{4}$ Université Rennes, UMR CNRS 6553 EcoBio/OSUR, Campus Beaulieu, 35000 Rennes, France

${ }^{5}$ Centre for Biodiversity Genomics, University of Guelph, 50 Stone Road East, Guelph, Ontario, Canada, N1G 2W1

*Corresponding author: Connor P.K. Warne, 226-820-6970, cwarne@uoguelph.ca 


\title{
Molecular evidence for multiple introductions of the banded grove snail (Cepaea nemoralis) in North America
}

K.K.S. Layton, C.P.K. Warne, A. Nicolai, A. Ansart, and J.R. deWaard

\begin{abstract}
:
Global identification and monitoring programs for invasive species aim to reduce imminent impacts to biodiversity, ecosystem services, agriculture and human health. This study employs a 658 base pair fragment of the cytochrome $c$ oxidase subunit I (COI) gene to identify and categorize clades of the banded grove snail (Cepaea nemoralis (Linnaeus, 1758)) from native (European) and introduced (North American) ranges using a maximum-likelihood phylogeny and haplotype networks. This work corroborates the existence of eight clades within Cepaea nemoralis and further identified three clades that were common to both Europe and North America (A, D, O). Clades A and D were found in eastern Canada, Ontario, and British Columbia, while clade $\mathrm{O}$ was restricted to Ontario, possibly introduced from Poland or central Europe. Haplotype networks suggest clade A was introduced from northern Europe while clade D was introduced from western and central Europe. Networks contained many private haplotypes and a lack of haplotype sharing, suggesting strong genetic structure in this system, possibly resulting from reduced dispersal in this species. This study describes the contemporary distribution of $C$. nemoralis in Canada and demonstrates the efficacy of DNA barcoding for monitoring the spread of invasive species, warranting its widespread adoption in management policies.
\end{abstract}


Key words: Cepaea nemoralis, banded grove snail, COI, invasive species, pest, origin, DNA barcoding

\section{Introduction}

Non-indigenous species (NIS) go largely unmonitored worldwide despite posing a grave threat to global biodiversity, commerce, and human health (Early et al. 2016). Their ecological impact is particularly devastating (Ricciardi et al. 2017), leading to the displacement and extirpation of native taxa, as seen in bumblebees (Morales et al. 2013) and freshwater mussels (Ricciardi et al. 1998), and through the introduction of new zoonotic diseases, such as in invasive white-toothed shrews (Nally et al. 2016). To further compound the crisis, the spread and establishment of NIS is predicted to increase due to continued globalization, habitat modification, and climate change (Early et al. 2016), as well as increased accessibility of new source species pools in their native ranges (Seebens et al. 2018). To combat the introduction, establishment, and spread of NIS, fast and cost-effective methods for their identification are imperative (Keller and Lodge 2017). DNA barcoding has proven effective for the identification and discovery of animal species on a global scale (e.g. Hebert et al. 2003), and it greatly increases the efficacy of monitoring and pest management programs (Armstrong and Ball 2005; Harris et al. 2017). It has also demonstrated utility in determining the provenance of NIS and can aid measures to halt their entry by identifying and verifying introduction pathways (Harris et al. 2017). 
The banded grove snail, Cepaea nemoralis (L.) (Gastropoda: Helicidae), has a native distribution across western and central Europe (Kerney and Cameron 1979) with an estimated 6,515 populations (Silvertown et al. 2011), but was introduced to North America several times: to New Jersey from England (Gould and Binney 1870), to Virginia from Italy (Reed 1964) and to Quebec from France (Örstan 2010). By 1928, C. nemoralis had spread to the Bruce Peninsula in Ontario (Pilsbry 1928) and west to British Columbia (Forsyth 1999). It is a known pest of agricultural areas, grasslands, gardens, greenhouses, viticultures, ornamentals and trees across its native range in Europe (Godan 1983) and now in North America, including in Ontario where $C$. nemoralis has become a vineyard pest, feeding superficially on grapevines (Martinson 1999). Despite its economic impact, and potential effect on natural ecosystems it has invaded (Whitson 2005; Forsyth 1999), little is known about the contemporary distribution of this species in North America.

The native range of $C$. nemoralis is better characterized, due in part to several studies exploring its mitochondrial diversity and historical range extension (Thomaz et al. 1996; Davison 2000; Grindon and Davison 2013). Grindon and Davison (2013) identified several mitochondrial lineages separated by deep divergences, confirming other studies that also found deep mitochondrial divergences in this species (Thomaz et al. 1996; Davison 2000). These eight clades or lineages, delineated with the barcode region of the cytochrome $c$ oxidase subunit I (COI) gene, were well supported and informative for tracking the human-facilitated dispersal of C. nemoralis in Europe (Grindon and Davison 2013). The distribution of these putative clades - or the mitochondrial diversity that defines them - has never been described for North America, but could improve our understanding of the origins, spread and provenance of the $C$. nemoralis invasion (Lindholm et al. 2005). The aim of this work therefore is to compile and compare DNA barcode 
records for $C$. nemoralis across its native and introduced range, to document the diversity and distribution of this NIS in North America, and shed light on the potential origins of its multiple introductions.

\section{Materials and methods}

Most specimens included in this study were sampled from nineteen European countries $(n=986)$ (Fig. 1). Specimens from North America were collected from Ontario $(n=117)$, Quebec $(n=9)$, British Columbia $(n=9)$, Newfoundland $(n=2)$ and Nova Scotia $(n=1)$ in Canada and from Virginia ( $n=2)$ in the US (Fig. 1). New specimens of $C$. nemoralis were collected by hand and preserved in $96 \%$ ethanol. A sample of foot tissue was used for molecular analysis following protocols in Ivanova et al. (2006) to amplify the barcode region of cytochrome $c$ oxidase subunit I (COI). Two primer sets were employed for PCR and sequencing: the universal 'Folmer' primers (LCO1490/HCO2198) (Folmer et al. 1994) and primers designed in this study (Cnem_F1: 5'AGTGGCTTATCTCTGTTAATTCG; Cnem_R1: 5'-CTTCGGGGTGACCAAAAAATCA). Amplicons were bidirectionally sequenced using BigDye v3.1 on an ABI 3730x1 DNA Analyzer (Applied Biosystems) following deWaard et al. (2017). Sequences were edited in CodonCode Aligner (CodonCode Corporation) and aligned by eye in Mesquite (Madison and Madison 2018). Sequences with greater than $1 \%$ ambiguous bases were removed from the dataset. Individual sequences were queried against the BOLD Identification Engine (http://www.boldsystems.org/index.php/IDS_OpenIdEngine) to check for contamination. Each sequence was also checked for stop codons and frame-shift mutations to protect against the inclusion of pseudogenes in the dataset. Additional sequence data were obtained from GenBank, 
various projects on the Barcode of Life Data Systems (BOLD, www.boldsystems.org), and from Grindon and Davison (2013), all of which went through identical quality screening. Specimen collection information and GenBank accession numbers are available in Table S1 and all data, sequences, electropherograms and primer details for each specimen are available in the public BOLD dataset 'DS-CEPNE' (doi:10.5883/DS-CEPNE). A multiple sequence alignment is provided in File S1.

Three closely related species were selected as outgroups [Cepaea hortensis (Müller, 1774), Caucasotachea vindobonensis (Pfeiffer, 1828), and Macularia sylvatica (Draparnaud, 1801)] for phylogenetic analysis. A total of 350 COI sequences of $C$. nemoralis and two of Caucasotachea vindobonensis were obtained from GenBank for this study (Table S1). A single representative from each unique barcode index number (BIN) was used for phylogenetic analysis, where a maximum likelihood (ML) tree was constructed in RAxML (Stamatakis 2006) using the raxmlGUI v1.3 (Silvestro and Michalak 2011) with rapid bootstrapping, a GTR $+\mathrm{G}$ model, and 1000 bootstrap replicates. Nodes with less than $60 \%$ bootstrap support were collapsed. TCS haplotype networks (Clement et al. 2002) were generated in PopART (Leigh and Bryant 2015) using 5000 iterations. The COI sequence alignments used for C. nemoralis clade A and D networks were trimmed to 578 bp and $473 \mathrm{bp}$, respectively. Haplotype networks were coloured based on the country or region of collection, across both its native and introduced ranges.

\section{Results}


A total of 1125 COI sequences of Cepaea were analyzed, with 220 derived in this study. The phylogenetic analysis recovered the same eight clades of $C$. nemoralis that were identified by Grindon and Davison (2013) in Europe (Fig. 2), confirming previous findings of a species complex, and proving similar to the extensive cryptic diversity observed in many other invertebrate taxa (e.g. Hebert et al. 2004; Witt et al. 2006). However, bootstrap support was low $(<60 \%)$ for a few nodes, most notably at the base of clade $C$; these nodes were subsequently collapsed (Fig. 2). Nonetheless, three well-supported clades are reported in North America (A, D, O) for the first time (Fig. 2). Clade A was found in four Canadian provinces (British Columbia, Ontario, Quebec, Newfoundland) and one US state (Virginia), in addition to its broad range in Europe (Belgium, Denmark, France, Germany, Ireland, Isle of Man, Italy, Netherlands, Norway, Poland, Sweden, Switzerland, and United Kingdom), that now includes Finland. Clade D was found in four Canadian provinces (British Columbia, Ontario, Quebec, Nova Scotia), and throughout Europe (Belgium, France, Germany, Ireland, Poland, Sweden, Spain, United Kingdom). In provinces with multiple clades, clade A was the most frequent clade in British Columbia, while clade D was the most frequent clade in Ontario and Quebec (Table 1). In addition to providing more sequence data for clades A and D in Europe, new collection localities for these clades were also determined, including new records for Denmark, France, Germany, Poland and Switzerland for clade A, and for France and Spain for clade D. Clade O was encountered infrequently, with only three samples from Poland and three from Toronto, Ontario. Additionally, the size of $C$. nemoralis populations in Europe appeared lower than in Canada in this study (personal observation, A. Nicolai).

Haplotype networks recovered a total of 134 haplotypes from 426 specimens of clade A (Fig. 3A), 60 haplotypes from 236 specimens of clade D (Fig. 3B), and two haplotypes from six 
specimens of clade O. Most haplotypes of clade A $(n=83)$ and $\mathrm{D}(n=34)$ were singletons and not shared between populations (Fig. 3), suggesting high genetic diversity in this complex or undersampling of various regions and populations (Muirhead et al. 2008). A total of 7 haplotypes of clade A and 15 haplotypes of clade D were found in North America, with 4 and 2 shared haplotypes, respectively. For clade A, both eastern and western North American haplotypes were most closely related to populations from Denmark, France, Germany, Norway, Poland, and Sweden, as defined by shared haplotypes, comprising mostly northern European countries (Fig. 3A). For clade D, eastern North American haplotypes were most closely related to haplotypes from Western Europe, including France and Spain, while western North American haplotypes were closely related to Belgium, Germany, and Poland (Fig. 3B); in the case of the latter, one haplotype $(n=23)$ was the most common clade D haplotype for British Columbia, Belgium, Poland, and Germany. Lastly, most specimens of clades B and C collected in this study were retrieved from the same European localities as reported in Grindon and Davison (2013), with the exception of a new country record for clade B: Germany.

\section{Discussion}

The banded grove snail can occupy a wide range of habitats (Silvertown et al. 2011) and has the capacity for great genetic adaptation (Ozgo 2011), which likely contributes to its successful invasion in the U.S. and Canada. However, until now, no study had examined $C$. nemoralis mtDNA diversity across its range in North America to understand the origin and extent of this invasion. Our analyses corroborate the presence of eight clades $(\mathrm{A}-\mathrm{G}, \mathrm{O})$ within $C$. nemoralis (Grindon and Davison 2013) and confirms its status as a cryptic species complex, 
although the base of clade $\mathrm{C}$ was poorly supported. We found three clades (A, D, O) of $C$. nemoralis that overlap between Europe and North America, which alone suggests the occurrence of either multiple invasion events or a single event including multiple clades with subsequent widespread dispersal. Clade A was found in British Columbia, Newfoundland, Ontario, Quebec and Virginia; clade D was found in British Columbia, Nova Scotia, Ontario, and Quebec; and clade O was found only in Ontario. In those provinces and countries containing multiple clades of $C$. nemoralis, clade A was the most frequent clade in British Columbia, France, Germany, Poland, Sweden, and the United Kingdom, while clade D was the most frequent clade in Ontario, Quebec, and Belgium. A difference in clade frequency across Canada strongly points towards multiple invasion events, albeit records are missing for adjoining states and provinces. The haplotype networks suggest an introduction of clade A to eastern and western North America from northern Europe, and two possible introductions of clade D from western Europe into eastern North America and central Europe into western North America. The fact that North American haplotypes within clades A and D appear to derive from different European locations provides further support for a multiple invasion scenario. In addition, clade $\mathrm{O}$ in Ontario shared a single haplotype with Poland, suggesting central Europe as the potential source. Two specimens of clade A from Virginia (USA), one of the documented introduction sites of C. nemoralis (Reed 1964), were more closely related to haplotypes from France and Switzerland than to those in Canada or Italy, the known introduction source for Virginia. It is possible that these haplotypes arise from other introduction events from France and Switzerland or represent incomplete sampling of Italian populations. These results do not provide strong support for a northward expansion of C. nemoralis from Virginia into Canada. Obtaining fresh specimens from the northeastern US for molecular analysis would provide insight into whether this location served as a source population for Ontario 
and the rest of eastern Canada. The networks also show little haplotype sharing and considerable structure, which may be due to large adult size rendering this species less dispersive than smaller land snails (Hausdorf and Hennig 2003). However, previous work has shown that this species is readily distributed through the horticultural trade, shipping between Europe and North America, and through tourism and other human movement (Örstan 2010; Grindon and Davison 2013).

Habitat preference and some life history characteristics of $C$. nemoralis are similar to that of the common garden snail, Cornu aspersum (Müller), another invasive pest across North and South America, Australia, New Zealand, and South Africa. Guiller et al. (2012) found that in some locations, C. aspersum was only able to successfully invade with multiple introductions, likely due to the severe population bottleneck experienced by the founding population. This may also explain the success of the $C$. nemoralis invasion in Canada, given the numerous introductions that have evidently occurred. Although Guiller et al. (2012) used microsatellite loci to track the invasion of C. aspersum, DNA barcoding provides an alternate tool for determining and monitoring of invasions, but at a lower cost, faster recovery, and universal application for all bilaterian animals. As such, many modern biosecurity and pest management strategies have now incorporated DNA barcoding (e.g. deWaard et al. 2010), since invasions of foreign species threaten global biodiversity, pose risks to public health, and reduce ecosystem services (Early et al. 2016). Efficiently identifying their point of origin is crucial to counteracting these effects, especially given the increased spread of NIS due to developments in terrestrial and aquatic transportation routes and the modification of habitats with global climate change (Early et al. 2016; Ricciardi et al. 2017).

This work has identified three clades of $C$. nemoralis in Canada and used these data to infer multiple introduction events and their probable source regions. Further sampling in both the native and introduced ranges of $C$. nemoralis, with particular emphasis on capturing and 
quantifying the haplotype diversity of each region, will further expose the links between its European and North American distributions. At present, C. nemoralis has been discovered in Newfoundland, Nova Scotia, Quebec, Ontario, and British Columbia, but future work should continue to sample in intermediate regions to determine the full range and genetic diversity of $C$. nemoralis across Canada. In addition, given the propensity for hybridization in some land snails (e.g. Harl et al. 2014), future work would benefit from incorporating one or more nuclear markers, to diagnose hybrids and their incidence, and to further untangle this cryptic species complex. Nonetheless, this work has highlighted the utility of DNA barcoding for tracking species invasions and range extensions, and we advocate for its routine use for these applications.

\section{Acknowledgments}

We thank Kareina D’Souza, Thanushi Eagalle, Jayme Sones, Monica Young, Crystal Sobel, Kate Perez (and other past/present members of the CBG Collections Team), participants of the Ontario BioBlitzes (www.ontariobioblitz.ca), Julie Jacquiery (UMR EcoBio, University Rennes), Paulina Kramasz (Jagellonia University, Krakow, Poland), the Sinclair lab and the Keyghobadi lab (Western University, London, Ontario) as well as their collaborators for aid in specimen collection. We also thank staff at the Canadian Centre for DNA Barcoding (CCDB) for aid in sequence acquisition. We are also grateful to Angus Davison (University of Nottingham), Jade Savage (Bishop's University), John Slapcinsky (Florida Museum of Natural History), Julien Brisset (Museum National d'Histoire Naturelle, Paris), Lars Hendrich (Zoologische Staatssammlung Muenchen; records from the BFB-Barcoding Fauna Bavarica project) and 
Marko Mutanen (University of Oulu) for providing additional sequence data for this manuscript. The Ontario Ministry of Research, Innovation and Science enabled this study through grants in support of the International Barcode of Life project (iBOL, www.ibol.org) while the Canada Foundation for Innovation provided essential infrastructure to the Centre for Biodiversity Genomics (CBG, www.biodiversitygenomics.net). The research unit UMR 6553 EcoBio provided financial support for sampling through a grant awarded by the working group InvaBio. An earlier version of this paper was improved by comments from two anonymous reviewers.

\section{References}

Armstrong, K., and Ball, S. 2005. DNA barcodes for biosecurity: invasive species identification. Philos. Trans. R. Soc. Lond. B Biol. Sci. No. 360: 1813-1823.

Davison, A. 2000. An East-West distribution of divergent mitochondrial haplotypes in British populations of the land snail, Cepaea nemoralis (Pulmonata). Biol. J. Linn. Soc. 70: 697-706.

deWaard, J.R., Mitchell, A., Keena, M.A., Gopurenko, D., Boykin, L.M., Armstrong, K.F., Pogue, M.G., Lima, J., Floyd, R., Hanner, R.H., and Humble, L.M. 2010. Towards a global barcode library for Lymantria (Lepidoptera: Lymantriinae) tussock moths of biosecurity concern. PLoS ONE, 5: e14280.

deWaard, J.R., Levesque-Beaudin, V., deWaard, S.L., Ivanova, N., McKeown, J., Miskie, R., Naik, S., Perez, K., Ratnasingham, S.R., Sobel, C.N., Sones, J., Steinke, C., Telfer, A.C., Young, 
A., Young, M.R., Zakharov, E.V., and Hebert, P.D.N. 2017. Expedited assessment of terrestrial arthropod diversity by coupling Malaise traps with DNA barcoding. bioRxiv: 192732.

Early, R., Bradley, B.A., Dukes, J.S., Lawler, J.J., Olden, J.D., Blumenthal, D.M., Gonzalez, P., Grosholz, E.D., Ibañez, I., Miller, L.P., Sorte, C.J.B., and Tatem, A.J. 2016. Global threats from invasive alien species in the twenty-first century and national response capacities. Nature Commun. 7: 12485 .

Folmer, O., Black, M., Hoeh, W., Lutz, R., and Vrijenhoek, R., 1994. DNA primers for amplification of mitochondrial cytochrome c oxidase subunit I from diverse metazoan invertebrates. Mol. Mar. Biol. Biotech. 3: 294-299.

Forsyth, R.G. 1999. Distributions of nine new or little-known exotic land snails in British Columbia. Can. Field-Nat. 113: 559-568.

Godan, D. 1983. Pest Slugs and Snails: Biology and Control. Springer-Verlag, Berlin, Heidelberg.

Gould, A.A., and Binney, W.G. 1870. Report on the Invertebrata of Massachusetts. Comprising the Mollusca. Wright and Potter, Boston.

Grindon, A.J., and Davison, A. 2013. Irish Cepaea nemoralis land snails have a cryptic Franco-Iberian origin that is most easily explained by the movements of mesolithic humans. PLoS ONE, 8: e65792. 
Guiller, A., Martin, M., Hiraux, C., and Madec, L. 2012. Tracing the invasion of the Mediterranean land snail Cornu aspersum aspersum becoming an agricultural and garden pest in areas recently introduced. PLoS ONE, 7: e49674.

Harl, J., Páll-Gergely, B., Kirchner, S., Sattman, H., Duda, M., Kruckenhauser, L., and Haring, E. 2014. Phylogeography of the land snail genus Orcula (Orculidae, Stylommatophora) with emphasis on the Eastern Alpine taxa: speciation, hybridization and morphological variation. BMC Evol. Biol. 14: 223.

Harris, A., Page, T.J., Fotedar, S., Duffy, R., and Snow, M. 2017. Molecular identification of the precise geographic origins of an invasive shrimp species in a globally significant Australian biodiversity hotspot. Biol. Invasions, 19: 463-468.

Hausdorf, B., and Hennig, C. 2003. Nestedness of north-west European land snail ranges as a consequence of differential immigration from Pleistocene glacial refuges. Oecologia, 135: $102-109$.

Hebert, P.D.N., Cywinska, A., Ball, S.L., and deWaard, J.R. 2003. Biological identifications through DNA barcodes. Proc. R. Soc. Lond. B. Biol. Sci. No. 270: 313-321. 
Hebert, P.D.N., Penton, E.H., Burns, J.M., Janzen, D.H., and Hallwachs, W. 2004. Ten species in one: DNA barcoding reveals cryptic specides in the neotropical skipper butterfly Astraptes fulgerator. Proc. Natl. Acad. Sci. U.S.A., 101: 14812-14817.

Ivanova, N.V., deWaard, J.R., and Hebert, P.D.N. 2006. An inexpensive, automation-friendly protocol for recovering high-quality DNA. Mol. Ecol. Notes, 6: 998-1002.

Keller, R.P., and Lodge, D.M. 2017. Species invasions from commerce in live aquatic organisms: Problems and possible solutions. BioScience, 5: 428-436.

Kerney, M.P., and Cameron, R.A.D. 1979. A field guide to the land snails of Britain and Northwest Europe. William Collins Sons and Co. Ltd., London.

Lindholm, A.K., Breden, F., Alexander, H.J., Chan, W.K., Thakurta, S.G., and Brook, R. 2005. Invasion success and genetic diversity of introduced populations of guppies Poecilia reticulata in Australia. Mol. Ecol. 14: 3671-3682.

Morales, C.L., Arbetman, M.P., Cameron, S.A., and Aizen, M.A. 2013. Rapid ecological replacement of a native bumble bee by invasive species. Front. Ecol. Environ. 11: 529-534.

Muirhead, J.R., Gray, D.K., Kelly, D.W., Ellis, S.M., Heath, D.D., and MacIsaac, H.J. 2008. Identifying the source of species invasions: sampling intensity vs. genetic diversity. Mol. Ecol. 17: $1020-1035$. 
Nally, J.E., Arent, Z., Bayles D.O., Hornsby, R.L., Gilmore, C., Regan, S., McDevitt, A.D., Yearsley, J., Fanning, S., and McMahon, B.J. 2016. Emerging infectious disease implications of invasive mammalian species: The greater white-toothed shrew (Crocidura russula) is associated with a novel serovar of pathogenic Leptospira in Ireland. PLoS Negl. Trop. Dis. 10: e0005174.

Örstan, A. 2010. Gastropoda, Pulmonata, Helicidae, Cepaea nemoralis (Linnaeus, 1758): New records for Montreal, Canada. Checklist, 6: 54-55.

Ozgo, M. 2011. Rapid evolution in unstable habitats: a success story of the polymorphic land snail Cepaea nemoralis (Gastropoda: Pulmonata). Biol. J. Linn. Soc. 102: 251-262.

Pilsbry, H.A. 1928. Helix nemoralis L. in Ontario. Nautilus, 42: 42-43.

Reed, C.F. 1964. Cepaea nemoralis (Linn.) in eastern North America. Sterkiana, 16: 11-18.

Ricciardi, A., Blackburn, T.M., Carlton, J.T., Dick, J.T.A., Hulme, P.E., Iacarella, J.C., Jeschke, J.M., Liebhold, A.M., Lockwood, J.L., MacIsaac, H.J., Pyšek, P., Richardson, D.M., Ruiz, G.M., Simberloff, D., Sutherland, W.J., Wardle, D.A., and Aldridge, D.C. 2017. Invasion science: A horizon scan of emerging challenges and opportunities. Trends Ecol. Evol. 32: 464-474. 
Ricciardi, A., Neves, R.J., and Rasmussen, J.B. 1998. Impending extinctions of North American freshwater mussels (Unionida) following the zebra mussel (Dreissena polymorpha) invasion. J. Anim. Ecol. 67: 613-619.

Seebens, H., Blackburn, T.M., Dyer, E.E., Genovesi, P., Hulme, P.E., Jeschke, J.M., Pagad, S., Pyšek, P., van Kleunen, M., Winter, M., Ansong, M., Arianoutsou, M., Bacher, S., Blasius, B., Brockerhoff, E.G., Brundu, G., Capinha, C., Causton, C.E., Celesti-Grapow, L., Dawson, W., Dullinger, S., Economo, E.P., Fuentes, N., Guénard, B., Jäger, H., Kartesz, J., Kenis, M., Kühn, I., Lenzner, B., Liebhold, A.M., Mosena, A., Moser, D., Nentwig, W., Nishino, M., Pearman, D., Pergl, J., Rabitsch, W., Rojas-Sandoval, J., Roques, A., Rorke, S., Rossinelli, S., Roy, H.E., Scalera, R., Schindler, S., Štajerová, K., Tokarska-Guzik, B., Walker, K., Ward, D.F., Yamanaka, T., and Essl, F. 2018. Global rise in emerging alien species results from increased accessibility of new source pools. Proc. Natl. Acad. Sci. U.S.A., 115: E2264-E2273.

Silvertown, J., Cook, L., Cameron, R., Dodd, M., McConway, K., Worthington, J., Skelton, P., Anton, C., Bossdorf, O., Baur, B., Schilthuizen, M., Fontaine, B., Sattmann, H., Bertorelle, G., Correia, M., Oliveira, C., Pokryszko, B., Ożgo, M., Stalažs, A., Gill, E., Rammul, U., Sólymos, P., Féher, Z., and Juan, X. 2011. Citizen science reveals unexpected continental-scale evolutionary change in a model organism. PLoS ONE, 6: 18-27.

Silvestro, D., and Michalak, I. 2012. raxMLGUI: a graphical front-end for RAxML. Org. Divers. Evol. 12: 335-337. 
Stamatakis, A. 2006. RAxML-VI-HPC: maximum likelihood- based phylogenetic analyses with thousands of taxa and mixed models. Bioinformatics, 22: 2688-2690.

Maddison, W. P. and Maddison, D. R. 2018. Mesquite: a modular system for evolutionary analysis. Version 3.51. https://www.mesquiteproject.org.

Thomaz, D., Guiller, A., and Clarke, B. 1996. Extreme divergence of mitochondrial DNA within species of pulmonate land snails. Proc. R. Soc. Lond. B Biol. Sci. 263: 363-368.

Whitson, M. 2005. Cepaea nemoralis (Gastropoda, Helicidae): The invited invader. J. Ky. Acad. Sci. 66: 82-88. 


\section{Tables}

Table 1. Frequency of each clade (A-O) of the banded grove snail (Cepaea nemoralis) in North America and Europe. Countries are abbreviated as follows: $\mathrm{BEL}=$ Belgium, $\mathrm{CRO}=$ Croatia, $\mathrm{DEN}=$ Denmark, FIN $=$ Finland, FRA $=$ France, GER= Germany, $\mathrm{HUN}=$ Hungary, IRE $=$ Ireland, ITA $=$ Italy, NET= Netherlands, NOR= Norway, $\mathrm{POL}=$ Poland, $\mathrm{SPA}=\mathrm{Spain}, \mathrm{SWE}=\mathrm{Sweden}, \mathrm{SWI}=$ Switzerland, UK= United Kingdom.

\begin{tabular}{|c|c|c|c|c|c|c|c|c|c|c|c|c|c|c|c|c|c|c|c|c|c|c|}
\hline \multirow[t]{2}{*}{ Clade } & \multicolumn{6}{|c|}{ North America } & \multicolumn{16}{|c|}{ Europe } \\
\hline & $\mathrm{BC}$ & ON & QC & NF & NS & USA & BEL & CRO & DEN & FIN & FRA & GER & HUN & IRE & ITA & NET & NOR & $\mathrm{POL}$ & SPA & SWE & SWI & UK \\
\hline A & 0.71 & 0.06 & 0.22 & 1 & - & 1 & 0.45 & - & 1 & 1 & 0.38 & 0.91 & - & 0.11 & 0.20 & 1 & 1 & 0.61 & - & 0.86 & 1 & 0.66 \\
\hline D & 0.29 & 0.91 & 0.78 & - & 1 & - & 0.55 & - & - & - & 0.19 & 0.08 & - & 0.07 & - & - & - & 0.34 & 0.27 & 0.14 & - & 0.01 \\
\hline O & - & 0.03 & - & - & - & - & - & - & - & - & - & - & - & - & - & - & - & 0.05 & - & - & - & - \\
\hline B & & & & & & & - & - & - & - & 0.09 & 0.02 & - & 0.07 & - & - & - & - & - & - & - & 0.23 \\
\hline C & & & & & & & - & - & - & - & 0.29 & - & - & 0.75 & - & - & - & - & 0.37 & - & - & 0.09 \\
\hline$E$ & & & & & & & - & - & - & - & - & - & - & - & 0.80 & - & - & - & - & - & - & - \\
\hline$F$ & & & & & & & - & - & - & - & 0.04 & - & - & - & - & - & - & - & 0.36 & - & - & 0.01 \\
\hline G & & & & & & & - & 1 & - & - & - & - & 1 & - & - & - & - & - & - & - & - & - \\
\hline
\end{tabular}




\section{Figure Captions}

Figure 1. Maps of C. nemoralis collection sites for clades $A, D$ and $\mathrm{O}$ in (A) its native range of Europe and its introduced range of (B) North America, with a detailed view of (C) Ontario, Canada. Maps were created using SimpleMappr (http://www.simplemappr.net).

Figure 2. Maximum likelihood (COI) tree for the $C$. nemoralis complex. Bootstrap supports are shown at each node. Triangles represent collapsed clades, hash marks denote branches that were truncated by half, and asterisks mark clades that were found in North America. Scale bar represents the number of substitutions per site.

Figure 3. TCS haplotype networks (COI) for C. nemoralis A) clade A and B) clade D. Hash marks indicate mutational steps and circle size corresponds to sample number. Putative ancestral haplotypes are marked in black. Black dashed boxes highlight sections of the network that contain North American haplotypes. 


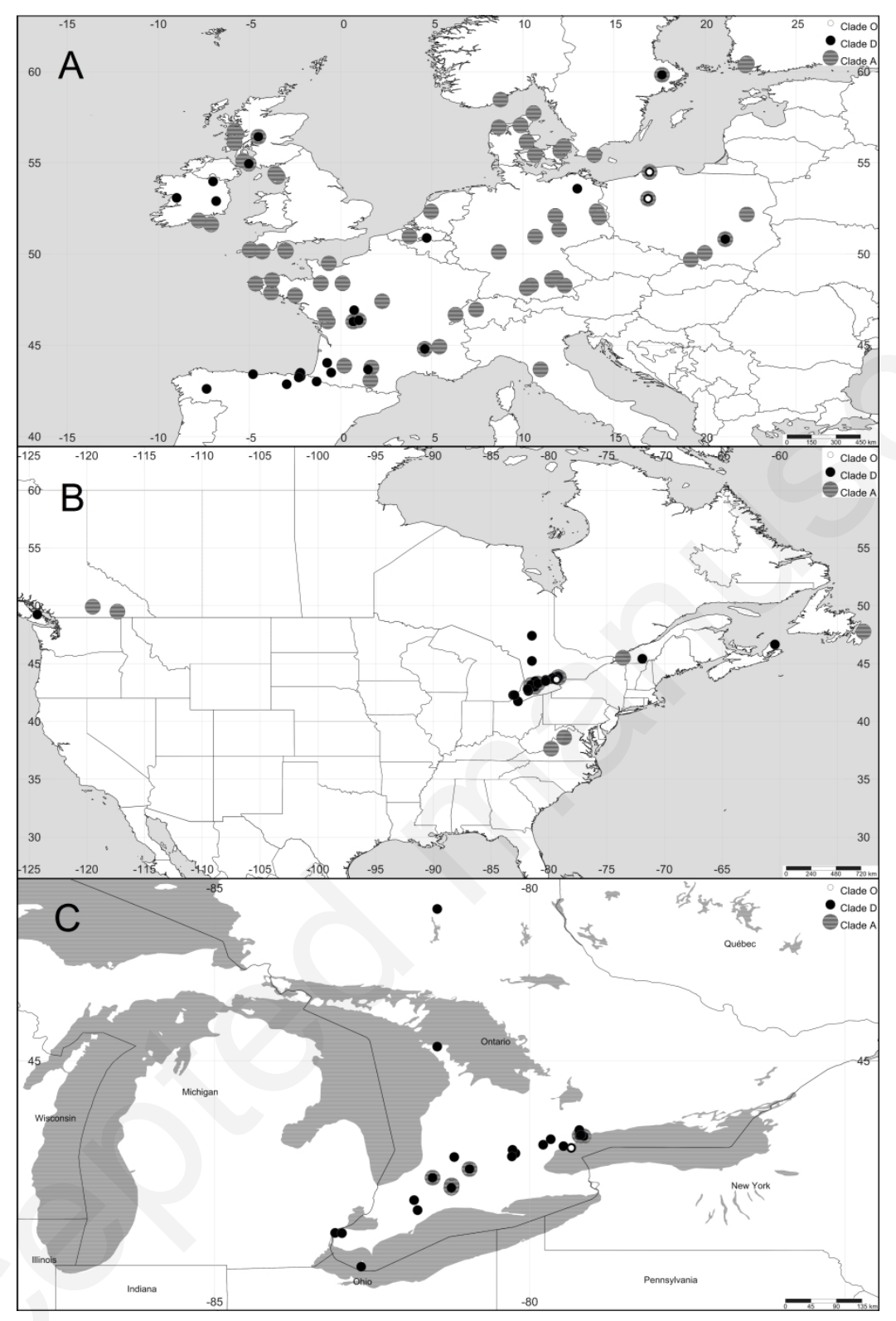




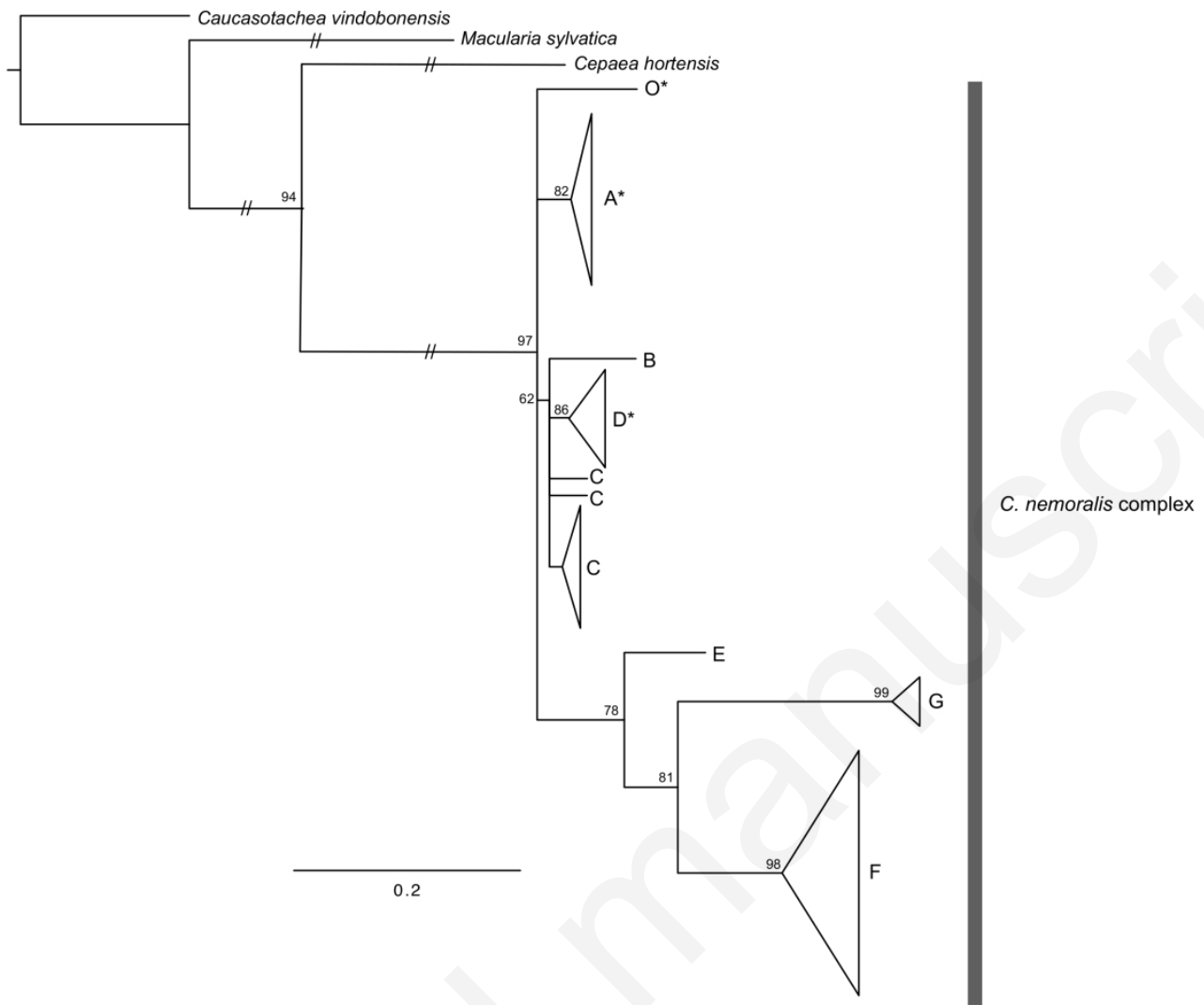

Figure 2. Maximum likelihood (COI) tree for the C. nemoralis complex. Bootstrap supports are shown at each node. Triangles represent collapsed clades, hash marks denote branches that were truncated by half, and asterisks mark clades that were found in North America. Scale bar represents the number of substitutions per site.

$255 \times 214 \mathrm{~mm}(300 \times 300 \mathrm{DPI})$ 


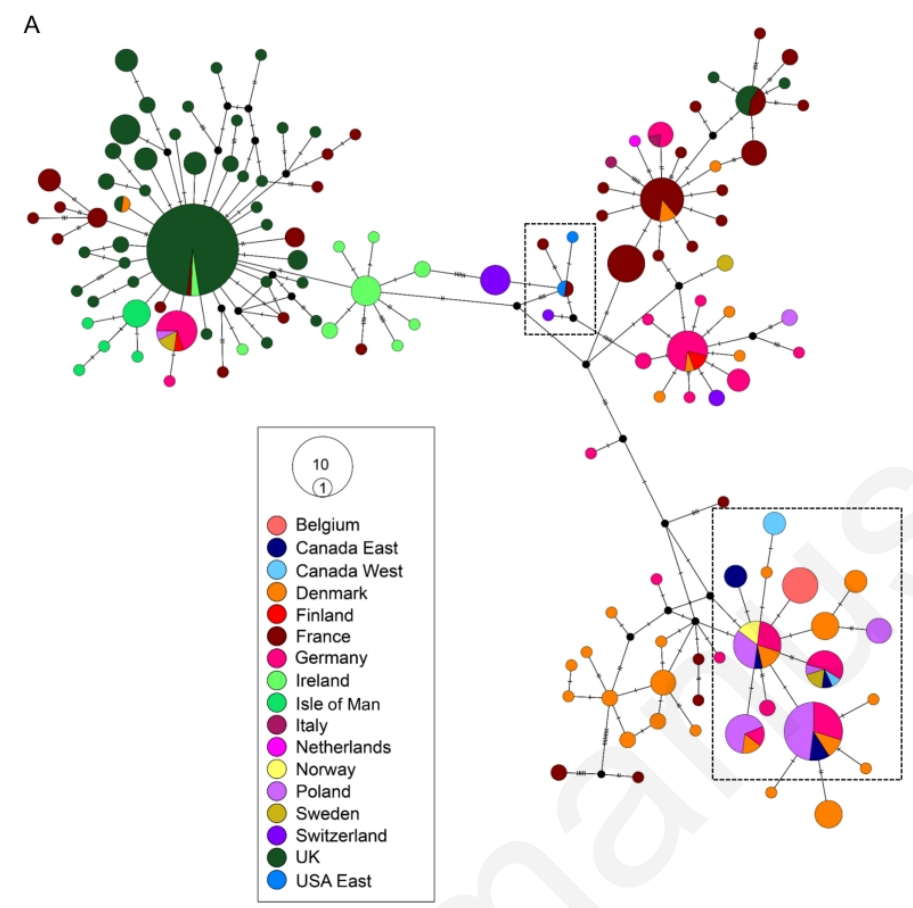

B

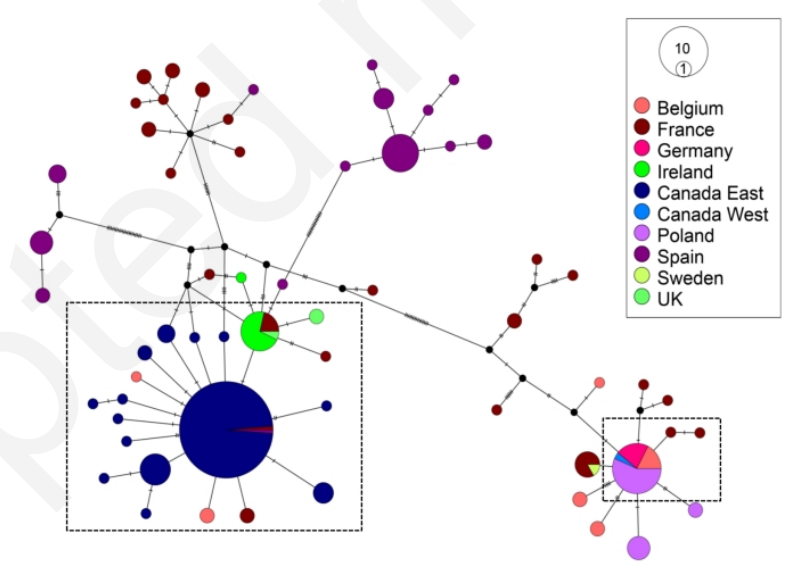

Figure 3. TCS haplotype networks (COI) for C. nemoralis A) clade A and B) clade D. Hash marks indicate mutational steps and circle size corresponds to sample number. Putative ancestral haplotypes are marked in black. Black dashed boxes highlight sections of the network that contain North American haplotypes. 